\title{
Socio-Economic Benefits of Trail Development in Conception Bay South
}

\author{
Jennifer Lake, Ec.D.
}

More and more communities are discovering that quality of place is an important factor in where people choose to live, work, and invest. Furthermore, access to interesting and scenic trails is a key component in the quality of place equation. Trails contribute to personal interaction, neighbourhood socialization, and community unity.

The railroad played an important role in the rich heritage of Conception Bay South. Preserving 18 kilometers of railway within the boundaries of Conception Bay South as a public trail (dubbed the T'Railway) will offer future generations the opportunity to experience the history of the Province and provide a means to incorporate the Town's local character and regional influence.

This paper will qualify the socio-economic benefits that can be realized with strategic, well-planned trail development specifically pertaining to the T'Railway in Conception Bay South. An overview of the Town of Conception Bay South, its vision for development, and the history of the T'Railway will be provided. It will be followed by a review of case studies and reports detailing the tourism potential and high-level economic and social benefits of trail development.

Keywords: trail development, economic benefits, socio-economic benefits, trail programming, railway redevelopment

\section{Introduction}

More and more communities are discovering that quality of place is an important factor in where people choose to live, work, and invest. Access to interesting and scenic trails is a key component in the quality of place equation, contributing to economic stimulation, property values, personal interaction, neighbourhood socialization, and community unity.

Bicycle and pedestrian facilities are proving to be a wise economic investment for communities. Studies have shown that they stimulate local economies by attracting bicyclists, hikers, crosscountry skiers and other tourists to the area. This in turn attracts and revitalizes businesses, creates jobs, and increases public revenue. Trails have a positive effect on nearby properties as homebuyers and business owners realize the value that such facilities bring to a community (Active Living Research, 2011).

Other important consequences of trails include improved self-image and social relationships, reduced crimes, a livelier community atmosphere, and a lifestyle which encourages young people to find entertainment in healthier and more wholesome ways. 
Trail development and ongoing maintenance can come at a significant cost for municipalities and trail interest groups, resulting in public funds being allocated elsewhere and thus slowing down or ceasing trail development. In contrast to this hesitation, residents have a strong appetite for more access to trails, and tourists are eager for experiential opportunities to get closer to nature. Hence, there is a need to determine the return on investment and benefits of trail development.

The vision for the development of the T'Railway in Conception Bay South is to facilitate recreational and health opportunities for residents and visitors that promote the use and preservation of natural resources, enrich quality of life, and celebrate the ways in which the town is unique. The development of the T'Railway is meant to be an expression of community pride and character and will be a means of preserving the natural and historical resources of the town.

This initiative is consistent with the following provincial government strategies and plans, which support trails as tourism and recreational assets:

- Active, Healthy Newfoundland and Labrador: A Recreation and Sport Strategy for Newfoundland and Labrador (Newfoundland and Labrador Department of Tourism, Culture and Recreation, 2007);

- Achieving Health and Wellness: Provincial Wellness Plan for Newfoundland and Labrador (Newfoundland and Labrador Department of Health and Community Services, 2006);

- Provincial Healthy Aging Policy Framework (Newfoundland and Labrador Department of Health and Community Services, 2010);

- Uncommon Potential - a Vision for Newfoundland and Labrador Tourism (Newfoundland and Labrador Department of Tourism, Culture and Recreation, 2009); and

- Tourism Product Development Strategy: A Special Place, A Special People, the Future for Newfoundland and Labrador Tourism, Main Report, 2004 (Newfoundland and Labrador Department of Finance, 2004).

It is fortunate that the province is on board with trail development because forming key partnerships will be essential in the development of trail systems. Working together to achieve these objectives would be a win-win situation for all, especially when complementary mandates and reduced financial resources are considered.

This paper will qualify the socio-economic benefits that can be realized with strategic, wellplanned trail development, and will use that information to justify continued investment in the T'Railway in Conception Bay South. An overview of the Town of Conception Bay South, its vision for development, and the history of the T'Railway will be provided, followed by a review of case studies and reports detailing the tourism potential and high level economic and social benefits of trail development. 


\section{The Town of Conception Bay South}

As per the Town's Municipal Plan 2011-2021, Conception Bay South is a family-oriented community which values its scenic coastline, landscape, waterways and recreational opportunities. The Town strives to ensure high standards of environmental protection, a vibrant commercial sector, and an efficient street network connecting safe, well-designed neighbourhoods that enable healthy and active lifestyles (CBCL Limited, 2012).

Conception Bay South will strive to be:

- A Town that strongly believes in the necessity of ensuring long-term community sustainability by balancing today's needs, trends, and limited resources against the potential impacts on future generations;

- A Town recognized for the quality of its built environment and the integration of the natural landscape throughout the community;

- A Town that celebrates its legacy as a friendly, family-orientated community that is respectful of its heritage yet welcoming to new growth and innovation;

- A Town that is well balanced in terms of local jobs, development, neighbourhood preservation, education, quality of life, transportation, finances, and citizen involvement; and

- A Town that ensures a good balance between residential, commercial, and industrial uses supported by quality infrastructure and transportation systems.

In order to achieve this vision, the Town's Municipal Council has established community development goals that provide the basis on which specific objectives and land use policies are based (See Appendix A).

The Town of Conception Bay South was incorporated in 1973 and has a population of close to 25,000, making it the second largest municipality in Newfoundland and Labrador. It is a linear community that stretches 26 kilometers along the south side of Conception Bay. The town is only 20 kilometers away from the provincial capital of St. John's, and connected to the city's international airport, vibrant downtown, and large population by excellent highway infrastructure.

Conception Bay South is experiencing tremendous growth in population and both residential and commercial development, which is expected to continue. Young families and older adults continue to choose Conception Bay South as a place to live because of its attractive location and amenities, and visitation continues to increase due to its proximity to the capital city. The beautiful coastline views and attractions --such as Foxtrap Marina, the Royal Newfoundland Yacht Club, Manuels River Hibernia Interpretation Centre and Linear Park, Conception Bay 
South Monument of Honour, and the future T'Railway — make Conception Bay South a bright town with a bright future.

Incorporated in 1973, the town has a population of close to 25,000 and has almost 500 businesses. Conception Bay South is a linear community of $26 \mathrm{~km}$, and its close proximity to the ocean is certainly an attraction in the region. The town has an excellent residential tax base in place due to the recent residential growth and focused efforts to capitalize on commercial and industrial growth opportunities.

The town has almost 500 businesses and expects many more to open as the gateway commercial development continues to move forward. The gateway is ideally positioned on a sprawling vista overlooking Conception Bay South. The vision of this development is to be a gateway for the region as well as a gateway that can connect residents to shopping, leisure and other experiences. The name speaks to the accessibility of the location between the capital city and the Western Avalon region, as well as the idea that you can arrive from any way, and you can go anywhere from here.

One of the business growth areas for Conception Bay South has been its tourism sector. The town is part of the Admiral's Coast Scenic Touring Route, which emerged from a regional project to identify a themed touring route for the area. It is believed throughout the community that this regional tourism initiative catalyzed tourism growth in the town, including the development of bed and breakfasts, a motel, a diving school, and an award-winning ocean adventure resort. While there have been advancements and increased activity from a tourism perspective within the town, there are many more untapped assets that could yield economic benefits if they were the focus of development.

From an industrial viewpoint, the town has a modern and active port managed by Transport Canada, an active pyrophyllite mine, and many light industrial ventures throughout the area. An industrial park on the eastern end of the town is nearing the construction phase and will be a welcome, long anticipated addition to the growing municipality.

\section{The Newfoundland T'Railway history and status}

In 1988 the railway line running across the Island of Newfoundland was abandoned. While an important chapter in the province's transportation history had drawn to a close, a new one was about to begin. In Newfoundland, 883 kilometers of abandoned rail bed provide the basis for a trail link between Port aux Basques on the west coast and the capital city of St. John's on the easternmost edge of the Avalon Peninsula. The Newfoundland T'Railway Provincial Parkofficially proclaimed as such on July 10, 1997-is being developed as a multi-use, all-season recreational trail by the T'Railway Council in conjunction with the provincial and federal governments, various municipal councils and local service districts, the Trans Canada Trail Foundation, and a number of other economic development organizations. 
The T'Railway development on the provincial level is being carried out in a number of phases, as funds become available. Much of the initial work carried out along the T'Railway involved brush cutting and general clean-up. Ditches were cleared of accumulated debris and trestles and bridges repaired. By 2006, the T'Railway Council had finished upgrading 50 of the 130 bridges and trestles on the T'Railway between Port aux Basques and St. John's. Then, in the spring of 2007, it began an ambitious, three-year program to complete the remaining 80 with $\$ 3$ million in funding from the Atlantic Canada Opportunities Agency, the Government of Newfoundland and Labrador, and the Trans Canada Trail Foundation. The work itself involved the installation of new decking and safety railing, improvements to bridge approaches, abutment enhancements, erosion protection, gravel backfilling and the erection of safety and information signs. In total, there are about 3.5 kilometers of bridges along the trail. This part of the project was carried out in three phases and was completed in the spring of 2010 (Newfoundland T'Railway Council, 2014). New finer grade material, better suited for walking and biking than the original heavy aggregate, has been spread to provide an even and well-compacted surface.

As previously stated, the T'Railway was designated a provincial park under Provincial legislation and thus, future upgrades and maintenance (particularly repairing damage from spring runoff and heavy snowmobile traffic) will be the responsibility of the Province. However, certain sections of the T'Railway have been leased by the province to other jurisdictions for further development, control and maintenance.

\section{Relevant Municipal Studies}

In 2002, the Conception Bay South Tourism Infrastructure Master Plan was completed. The plan identified a number of tactics that might be used to increase visitation from the neighbouring City of St. John's. The study identified a number of product development initiatives that should be undertaken to enhance the town's capacity to attract and manage tourists. The plan suggested dividing the town into tourism management areas and identified the T'Railway as an important tourism link to St. John's via a proposed bicycle path. The path would link Conception Bay South to the network of trails in neighbouring towns (Tract Consulting Inc., 2002).

In 2007 the Conception Bay South T'Railway Study identified the opportunity for the T'Railway to serve as the 'spine' of an integrated system of parks and trails in the town. The plan suggested an incremental development of the T'Railway which would see the current motorized use cease. The future T'Railway would accommodate bicycles and pedestrians only, and a new ATV bypass would be constructed to accommodate motorized recreation vehicles (Tract Consulting Inc., 2007).

In the Conception Bay South Open Spaces and Recreation Master Plan (Tract Consulting Inc, 2008), residents of the community identified their most important recreational need as more walking trails. The redevelopment of the existing 18 kilometer T'Railway route offers an unequalled opportunity to fulfill this need as well as provide the pedestrian link between many of 
the town's trails and recreational facilities. It is envisioned that the T'Railway will be the premier recreation asset in the town, and will be unprecedented as a multi-use linear park in the Province (Tract Consulting Inc., 2008).

In 2011, Tract Consulting completed the Conception Bay South T'Railway Development Plan (Tract Consulting Inc., 2011). This plan outlined a series of phases that would lead to the enhanced development of the T'Railway as a pedestrian and bicycling trail complete with parks and playgrounds, staging areas, heaving landscaping, wharves, and gates to prohibit vehicular access. The plan also contained a design for the development of a 28 kilometer back country bypass trail for motorized use. The next steps for both developments were detailed in the plan, which also included recommendations to implement future enforcement, public education and maintenance plans.

A 2012 provincial resident survey noted that $27 \%$ of those who travel reported using trails during their last in-province vacation. Of all visitors to Newfoundland and Labrador, $15 \%$ reported pleasure walking in and around communities as an activity during their last vacation in the province (Newfoundland and Labrador Department of Tourism, Culture and Recreation, 2012).

It is clear that the Town of Conception Bay South has a desire to develop the T'Railway. Since 2002, all of the relevant studies indicate that the T'Railway would be a strategic addition to the town. However, recognizing the need to develop the T'Railway is not the same as understanding why to build it and how it will benefit residents and the community as a whole, will be evidenced throughout this paper. It is time to fill in the knowledge gaps so that strategic steps can be taken to turn the vision into a reality.

\section{Benefits of trail development}

For communities that have strong leadership, a pro-active vision, and the willingness to take ownership, there are vast opportunities for tourism development and increased economic benefits to be realized. The effects of trail infrastructure on communities are outlined in the following pages and are attainable with proper planning, commitment and direction. The socio-economic benefits are described at a high level and many facets of strategic implementation will be required to achieve the benefits at the most optimum level.

The following sections will look at the economic benefits of trails, followed by the social and environmental benefits.

\section{Tourism development}

Avid pedestrians and bicyclists are known to spend dollars on their respective activities. Walkers ensure proper footwear and clothing are purchased, while bicyclists often put out substantial sums for the right mountain bike. Walkers from other areas, including out-of-province, will travel long distances to where they may experience new walks and will promote their experience 
to others. This raises the profile of the community and increases its attractiveness as a destination (Active Living Go for Green, 1996). The T'Railway in Conception Bay South has an added feature: it can be linked to the Grand Concourse walkway network via neighbouring municipalities, thus allowing pedestrians and bicyclists a safe route right into the City of St. John's (Grand Concourse Authority, 2013). The 2003 Exit Survey conducted by the Provincial Department of Tourism, Culture and Recreation noted that $80 \%$ of the non-resident visitors participated in pleasure walking or hiking as an activity while visiting the province (Newfoundland and Labrador Department of Tourism, Culture and Recreation, 2003).

Determining the direct economic impacts of trails to a community will vary greatly depending on the length of a trail, the amenities along the trail and whether the trail is part of a well-connected network. Throughout the research for this paper, sources referenced a variety of ranges of spending by trail users within a community. However, the minimum estimate was approximately $\$ 20.00$ per person. Using that variable with the 96,000 user count recorded in 2011 of the East Coast Trail, bordering Conception Bay South, it could be estimated that approximately $\$ 1.9$ million dollars was deposited throughout the communities along the East Coast Trail in one year. Over five years, assuming the same variables, the economic spinoffs are almost $\$ 10$ million dollars (East Coast Trail Association, 2011).

Trail tourism is one attraction that can be leveraged by places that are not well-developed tourism destinations. According to many tourism industry associations, more people are seeking experiential tourism destinations "off the beaten track" since they have already done the Caribbean, Disney and Vegas vacations. Many day and overnight visitors engaging in trail tourism are economically well-off with significant discretionary income (American Trails, 2013). Surveys conducted by the East Coast Trail Association and Gros Morne National Park strongly support the importance of trail infrastructure to increased visitation, extended stays, and repeat visitation. Other research, like that included in the Travel Activity and Motivation Survey (TAMS), also shows the importance of walking and hiking trails to visitors to Canada.

There are places that invite visitors from around the world to come and enjoy the outdoors that might not have the offerings of Disney World or the Grand Canyon with commercialized attractions and events but offer up close and personalized experiential interactions. A new twist on tourism is becoming more evident where small town hospitality keeps tourists coming back. To add to the twist, a fully developed coastline trail is what some tourists will look for, and ultimately, they find the town because of the trail. For example, hiking enthusiasts have found the rural town of Bay Bulls located on the southern shore of Newfoundland and Labrador because they went to the province to hike the world renowned East Coast Trail. Business owners and residents of towns such as Bay Bulls which are adjacent to such trail networks, rely on such assets for economic prosperity and are generally extend the very warm, welcoming and personalized hospitality that these visitors seek and expect. They leave talking about the East Coast Trail, but now, they also talk about their experiences in the Town of Bay Bulls. (Hennebury, 2013). 
The Great Allegheny Passage region in southwestern Pennsylvania and western Maryland has developed a program to use trails to encourage economic development. The Trail Town Program's purpose is to ensure that trail communities and businesses maximize the economic potential of the trail that runs through nine communities in the region. The Allegheny Trail Alliance with funding from Pennsylvania's Department of Conservation and Natural Resources, and with planning and fundraising help from The Progress Fund, developed the Trail Town concept in the early 2000s. The program launched in January 2007, and expanded into western Maryland in 2009. The Program goals are to retain, expand, and increase revenues of existing businesses, recruit sustainable new businesses, facilitate collective action by the Trail Towns to create a world-class recreational destination, and to improve the buildings and infrastructure in each town to create a visitor friendly destination (Allegheny Trail Alliance, 2010).

Basic elements of a Trail Town strategy include enticing trail users to get off the trail and into the town, welcoming trail users by making information about the community available on the trail, making safe connections between the town and the trail, educating local businesses on the economic benefits of meeting trail users' needs, attracting new businesses or expanding existing ones to fill gaps in the goods and services that trail users need, and promoting the 'trail friendly' character of the town.

A specific example of the success of the program is an accidental "International Week" that occurred at the Parker House Country Inn in Confluence, PA. Each day of this particular week, the Inn received new guests from around the world that were using the trail. Australians visited Monday, Canadians on Tuesday, South Africans on Wednesday, Germans on Thursday and Austrians on Friday. Such an event hadn't been planned but it just happened, expanding the Inn's clientele in unexpected ways. An experience such as this may be normal for places like London or New York City, but for rural Pennsylvania, it was a big deal. It's just one example of the valuable tourism impact trails can have on the economic health of rural communities along the Passage (Gallagher and Camp, 2011).

Because of the nature of the T'Railway and its connectivity to neighbouring municipalities, there is potential to develop a Trail Town Program and partner with neighbouring municipalities to promote the entire trail corridor as a tourist destination. The establishment of a Trail Town Program could have great economic benefits within the region and will need strategic attention moving forward. The creation of a sustainable business network with a regional agenda could address issues and identify collective opportunities among the neighbouring municipalities. This would result in a more effective product for trail users. Combined efforts could also result in economic research activities, annual trail counts, trail-wide marketing and promotional campaigns, installation of signage, informational kiosks, and preservation planning.

It is clear from the Great Allegheny Passage example that trails attract tourists who help create local jobs and put money into local economies; but for any tourism efforts to flourish, including trails, the 4 A's of tourism must be evaluated: Attraction, Access, Accommodation and 
Advertising. The T'Railway in Conception Bay South has obvious tourism potential because it is attractive, accessible, has accommodations in close proximity, and will have an extensive marketing plan attached to it. However, it is important to recommend that an in-depth analysis of trail tourism, including checklists as outlined in Trails and Tourism, should be used as a framework for building the 4 A's into a strategic plan to ensure success of the T'Railway in Conception Bay South (Ontario Trails Council, 2004).

\section{Business development}

Businesses want to locate where people want to live. People want to live in a municipality with a good mix of services that improve quality of life. Having a fully developed trail destination running from one boundary of the Town to the other not only makes a municipality unique, lending to its competitive advantage, but also enhances business attraction. With the development of a significant trail system such as the T'Railway in Conception Bay South, businesses retailing bicycles, trail apparel and tour operators will more likely find the Town attractive from a business perspective.

Promoting business along trails and recreation routes enhances the appeal of a town for residents and visitors, while at the same time growing the business community. In turn, it strengthens the local economy. A great resource that details many strategies for promoting the use of trails for bicyclists is Bicyclists Bring Business: A Guide for Attracting Bicycle Tourists to New York's Canal Communities (Active Living Research, 2010). The strategies within this guide are worthy of further research for potential implementation. There are assessment checklists included in the guide that will guide business owners to build a bicycle-friendly business, and help municipal leaders to create a bicycle-friendly community and strategies on reaching out to bicyclists now and in the future.

Commercial properties off the trail can benefit as well. It has been reported that bicycle and pedestrian trails attract high quality businesses by providing commuting options for employees, scenic places for stress free strolls at lunchtime, and safe, convenient sites for family recreation. Choosing a location that will help attract and retain key personnel was cited as the number one factor in selecting office locations, and corporate real estate executives have said employee quality of life issues are as important as cost when deciding where to locate a new businesses (National Bicycle and Pedestrian Clearinghouse, 1995).

A good example of a trail contributing to business development is the $376 \mathrm{~km}$ Katy Trail, which traverses nine counties and adjoins 35 towns in Missouri, which range in population from 60 to 60,000 . These communities, many in economic decline since the railroad's demise, were initially opposed to the trail; but when the first sections opened, sentiments changed. Visitors flocking to the new rail-trail proved to be responsible, likable guests who needed goods and services available in the towns. Within weeks of the trail dedication, new and old businesses were vying for tourist dollars. Restaurants, bed and breakfasts, bicycle rental shops, antique dealers, 
campgrounds and gift shops all opened to meet the needs of hundreds of thousands of visitors (National Bicycle and Pedestrian Clearinghouse, 1995). Although the length of the T'Railway in Conception Bay South is only $18 \mathrm{~km}$, its development would be part of a larger network already developed to the east, which collectively would make the entire network approximately $50 \mathrm{~km}$.

Hiking and outdoor recreation is a booming business. An organized trail system is a desirable amenity that can contribute to the economic vitality of the community. A trail can guide both visitors and residents through diverse neighbourhoods, past interesting shops, historical landmarks, and many other businesses in downtown areas. Revenue generated from trail-related recreation and sports activities provide substantial income and employment opportunities (Barthlow \& Moore, 1998).

\section{Tax base development}

Opportunities for significant positive change exist for communities who offer shared-use nonmotorized trails. A case study of the Ludlam Trail corridor in Miami identifies numerous social, environmental, and economic benefits of a high quality "spine" trail running through the middle of a community and connecting attractions and amenities. Key benefits included acting as a catalyst to the redevelopment of existing or under-utilized commercial properties, and enhancing accessibility to shopping for residents (AECOM, 2010). An integrated trail system will further contribute to community economic development through increased tax revenues from new businesses, new residents/workers, additional retail sales and higher property values (AECOM, 2010). The Active Living Research program (administered by the University of California, San Diego) supports this finding. Their report, Economic Benefits of Open Space, Recreation Facilities, and Walkable Community Design, cites that trail systems are believed to generate economic benefits to local governments, home owners and businesses through higher property values and correspondingly higher tax assessments (Active Living Research, 2010). Nicholls and Crompton note that "linear green spaces, maximize the number of properties that can be positioned adjacent or nearby to them. As a result, a higher number of property values are enhanced, saleability rates are higher, and the impact on the property tax base is greater" (2005, 339-340). The authors further concluded that a single trail corridor in Austin, Texas increased the property value of adjacent properties by $\$ 13.64$ million (Nicholls \& Crompton, 2005).

The Midtown Greenway in Minneapolis stands as a good example of how focussed planning and outreach for trail development can help to enhance economic development among a trail corridor. The first phase of the Greenway was opened in 2000, converting a rail line trench into a new neighbourhood amenity. However, the depressed former rail bed was not well connected to communities around the trail. During the next several years, members of the Midtown Greenway Coalition worked to create zoning and land use plans designed to provide enhanced access to the trail. The initiative was a success, spurring new nodes of development along the corridor thanks to the new trail amenity and good planning (Rails to Trails Conservatory, 2007). 


\section{Health and Well Being}

Increased tourism potential, business attractiveness, tax revenues, and economic spinoffs are only some positive economic benefits to trail development in a municipality. The health benefits of trails are also considerable in that they prevent obesity and the illnesses associated with it. This consideration is consistent with the federal government's mandate to encourage exercise as an important contributor to a healthy lifestyle, both for individuals and families (American Trails, 2007). Trails are the recreational infrastructure in a community that may be the most attractive to the widest range of people, including persons with disabilities, children and youth, the elderly and others who are prone to be less physically active.

Active transportation opportunities in Conception Bay South will become more evident with the development of the T'Railway, creating more liveable communities and more active residents. A recent webinar on the Economic Impact of Trails noted that just three hours of bicycling per week can reduce a person's risk of heart disease and stroke by 50 percent (American Trails, 2013). The growing trends of walking and bicycling are evident by the option to view routes on Google Maps. Prior to 2010, Google Maps' most requested feature was biking directions, which was delivered that year after the tech company received a petition with 50,000 signatures (Gannes, 2010). By simply searching a location, choosing a destination and clicking the walking or cycling button, the service generates the best routes.

A U.S. Centre for Disease Control handbook, Promoting Physical Activity Among Adults, states that "...the most effective activity regimens may be those that are moderate in intensity, individualized, and incorporated into daily activity" (National Bicycle and Pedestrian Clearinghouse, 1995). T'Railway users will have the opportunity to integrate moderate, individualized exercise with their daily trips to work, school, personal errands, or appointments should they choose to. Such physical activity helps prevent heart disease, diabetes, osteoporosis, obesity, and colon cancer. An increase in physical activity reduces stress and improves mental health. Moderate exercise is also known to protect against injury and disability because it builds muscular strength and flexibility, which helps to maintain functional independence in later years of life (American Trails, 2007).

Bicycling and walking offer many health benefits not only for individuals, by improving physical health and quality of life, but also for society, by reducing demand for health care. According to a National Park Service Study, people who exercise regularly have 14 per cent lower claims against their medical insurance and spend 30 per cent fewer days in hospital (American Trails, 2007).

Being physically active is more than a personal decision. Community design and the availability of open spaces and recreation areas strongly influence how active people are. Living close to parks and other recreation facilities also is consistently related to higher physical activity levels for both adults and youth (American Trails, 2007). Improving the walkability of neighbourhoods 
and increasing access to recreation opportunities are essential strategies for preventing childhood obesity and developing healthier people.

\section{Community cohesion}

Trails can offer an abundance of opportunities for volunteering in a community; among them are clean-up initiatives, informal monitoring of trail activity and conditions, and involvement in trail education and community event planning. Partnerships among community groups, businesses, property owners, municipal and provincial governments, and residents can be solidified through a trail where collective pride and ownership prevails. Regular trail-based recreation and special events, such as Trail Days, engage people of all income brackets, all age groups and all cultures - meanwhile building stronger neighbourhoods.

\section{Safety}

The T'Railway in Conception Bay South, in its current condition and with its current uses, is extremely unsafe for all users. Safety is further compromised by off-road vehicles using town streets to access the T'Railway. The lack of proper signage and regulatory control also make the T'Railway unsafe. Development has to occur if accidents are to be avoided and if the T'Railway is to be an asset for the Town.

The T'Railway runs through an increasingly urbanized area of the Town which continues to grow in leaps and bounds. The urbanization is not compatible with motorized uses on the T'Railway, and the population increase means there is a greater number of residents who are looking for opportunities to walk or bicycle for health and recreation.

Therefore, if the T'Railway is developed, it will transform the route from an unsafe environment to a safe and regulated one. The development of this trail within Conception Bay South can provide a safe and convenient transportation option, which can connect communities to some schools, workplaces, commercial and cultural centres, historic sites and provide access to the coastline.

\section{Environmental benefits}

Providing a connected trail system will likely decrease motorized trips and increase walking and bicycling, resulting in reduced pollution. The increase in the level of walking and bicycling due to the development of such facilities leads to a cleaner environment and healthier population while providing convenient access to the outdoors for enjoyment and relaxation.

Unfortunately, millions of dollars are still being spent by consumers in purchasing, operating and maintaining vehicles, an investment that leads to fuel consumption, emissions, and traffic congestion. Road and highway construction and maintenance, oil production, and other forms of environmental damage add to the costs of motor vehicle use. Studies indicate that $50 \%$ of car excursions are less than five kilometers, a distance that could be easily walked or biked (National 
Bicycle and Pedestrian Clearinghouse, 1995). Using human-powered transportation could result in large monetary savings for consumers, savings on motor vehicle mileage, decreased gas usage and less exhaust emissions annually.

Trails lead users to diverse plant and animal habitats, like wetlands and forested areas, as well as to lands with historic significance. With proper signage and education initiatives, special features can be enhanced resulting in an increased appreciation of natural and cultural heritage. By leading users along specific pathways, users are kept away from more sensitive features that might not be able to withstand traffic. Environmental buffers can be strategically placed to protect delicate wetlands while still allowing users to experience a variety of plant and animal wildlife.

Users need to be educated about the diverse ecosystems and become aware of the significant natural and cultural heritage features that can be appreciated through trail use. Educating young people about trails and giving them trail experiences will build a network of trail stewards for the future.

\section{Conclusion}

Trails and green spaces are important community amenities that help to spur economic development. From home owners choosing to live along a park-like trail, to bicycle tourists making their way through a trail system, trails are important infrastructure attracting people and dollars. Trails are economic engines for community revitalization. Through careful planning, communities are realizing the full economic potential of linking trails and local businesses.

By consciously linking trails and businesses, and providing new desirable housing choices along trails, communities are building vital, economically stable neighbourhoods that are more sustainable (Rails to Trails Conservatory, 2007). Bicycling and pedestrian facilities enhance the quality of life for many individuals. Ecological services, greenhouse gas reductions, and mental health benefits, as well as recreation and physical health benefits, are positive indirect effects of trails on communities.

In Conception Bay South, public education on many of the social and economic benefits of trail use, supported by enforcement and maintenance plans, will provide the T'Railway the new exuberance it deserves. Further exploration of a motorized back country trail should be a priority for Town officials as it will provide a safe, scenic route for local motorized trail users and provide a unique tourism product offering in the region.

It is evident that trails can be powerful tools for economic development, however much work is needed to ensure trail systems are implemented properly and initiatives tailored to achieve maximum usage and benefits. With strong partnerships in place and dedicated leadership, the T'Railway in Conception Bay South has the potential be the coastline trail of choice connecting 
the urban core of the province with regional rural areas, capitalizing on the multitude of socioeconomic benefits for both residents and tourists.

\section{Author biography}

Jennifer Lake is a lifelong resident of Conception Bay South, Newfoundland and Labrador. Jennifer is employed by the Town's Economic Development and Tourism Department and has a Certificate in Economic Development from the University of Waterloo, a Bachelor Degree in Physical Education with a Concentration in Teaching from Memorial University, and in September 2013 was the first economic development professional in the province of Newfoundland and Labrador to receive her Ec.D. Designation from the Economic Developers Association of Canada. Jennifer is currently working towards completing her Fellowship Designation.

\section{References}

Active Living Go for Green (1996). Developing Communities for Active Transportation: The Active Living and Environment Program.

Active Living Research (2011, May). Bicyclists Bring Business: A Guide for Attracting Bicycle Tourists to New York's Canal Communities. Retrieved from www.AmericanTrails.org/resources/economics

Active Living Research (2010, May). Economic Benefits of Open Space, Recreation Facilities, and Walkable Community Design. Retrieved from

www.AmericanTrails.org/resources/economics

AECOM (2010, May). Ludlam Trail Study. Retrieved from www.AmericanTrails.org/resources/economics

Allegheny Trail Alliance (2010). Trail Town Program, a Resource for Businesses along the Great Allegheny Passage. Retrieved from http://www.trailtowns.org/

American Trails (2007). Health-Based Benefits of Parks, Trails and Open Space. Retrieved from http://www.americantrails.org/resources/benefits/HealthGrnwy.html

American Trails (2013). Economic Impacts of Trails Webinar. Retrieved from www.AmericanTrails.org/resources/economics. 
Barthlow, Kelly, \& Moore, Roger (1998). The Economic Impacts and Uses of Long-Distance Trails. Retrieved from http://ntl.bts.gov/lib/12000/12200/12275/12275.pdf

CBCL Limited (2012, April). Town of Conception Bay South Municipal Plan 2011-2021.

East Coast Trail Association (2011). User Counts recorded by laser counters. Retrieved from www.eastcoasttrail.cal

Gallagher, Marlee \& Camp, Amy (2011, Summer). Trail Towns benefit from visitor spending: Enhancing trail tourism along the Great Allegheny Passage. American Trails Magazine, 10-11.

Gannes, Liz (2010, March 9). Google Maps Adds Biking Directions. Gigaom. Retrieved from http://gigaom.com/2010/03/09/google-maps-adds-biking-directions/

Grand Concourse Authority (2013). Retrieved from www.grandconcourse.ca

International Mountain Bicycling Association (2008). Technical Assistance Series, Number 2:

The Economic and Social Benefits of Off-Road Bicycle and Pedestrian Facilities, Washington, DC. Retrieved from

http://www.thunderheadalliance.org/site/images/uploads/EconomicSocial_Benefits_Off$\underline{\text { Road_BikePed_Facilities.pdf }}$

Newfoundland and Labrador Department of Finance (2004). Tourism Product Development Strategy: A Special Place, A Special People, The Future for Newfoundland and Labrador Tourism, Main Report. Retrieved from www.fin.gov.nl.ca/fin/faq/hnl_report.pdf

Newfoundland and Labrador Department of Health and Community Services (2006). Achieving Health and Wellness: Provincial Wellness Plan for Newfoundland and Labrador. Retrieved from www.health.gov.nl.ca/health/publications

Newfoundland and Labrador Department of Health and Community Services (2007). Provincial Healthy Aging Policy Framework. Retrieved from http://www.releases.gov.nl.ca/releases/2007/health/0711n04HA\%20Policy\%20Framework.pdf

Newfoundland and Labrador Department of Tourism, Culture and Recreation (2003). Exit Survey Program Highlights. Retrieved from http://www.tcr.gov.nl.ca/tcr/publications/2003/ExitSurvey_ProgramHighlights_2003.pdf 
Newfoundland and Labrador Department of Tourism, Culture and Recreation (2007). Active, Healthy Newfoundland and Labrador: A Recreation and Sport Strategy for Newfoundland and Labrador. Retrieved from www.tcr.gov.nl.cs/tcr/publications

Newfoundland and Labrador Department of Tourism, Culture and Recreation (2009). Uncommon Potential - a Vision for Newfoundland and Labrador Tourism. Retrieved from www.uncommonpotential.com

Newfoundland and Labrador Department of Tourism, Culture and Recreation (2012, January). Resident Travel Survey Summary Report. Retrieved from http://www.tcr.gov.nl.ca/tcr/publications/2010/2010_Resident_Travel_Survey_Final_Report.pdf

Newfoundland T'Railway Council (2013). Retrieved from www.trailway.ca

Nicholls, Sarah \& Crompton, John (2005). The Impact of Greenways on Property Values: Evidence from Austin, Texas. Journal of Leisure Research, 37(3), 321-341. Retrieved from http://agrilife.org/cromptonrpts/files/2011/06/4_2_7.pdf

Ontario Ministry of Tourism and Recreation (2004). Travel Intention Survey.

Ontario Trails Council (2004). Summary of "Trails and Tourism" presentation at Ontario Trails Council 2004 Annual General Meeting. Retrieved from www.ontariotrails.on.ca

Rails to Trails Conservatory (2007, August). From Trail Towns to TrOD: Trails and Economic Development. Retrieved from http://www.railstotrails.org/index.html

Tract Consulting Inc. (2002). Conception Bay South Tourism, Marketing \& Infrastructure Development Plan.

Tract Consulting Inc. (2007). Conception Bay South T'Railway Study. Retrieved from http://www.conceptionbaysouth.ca/wp-content/uploads/2012/01/CBS_TRailWay_Study.pdf

Tract Consulting Inc. (2008). Town of Conception Bay South Open Space/Recreation Master Plan. Retrieved from http://www.conceptionbaysouth.ca/wpcontent/uploads/2012/08/FINAL\%20REPORT\%20July\%202008.pdf

Tract Consulting Inc. (2011). Town of Conception Bay South T'Railway Development Plan. 


\section{APPENDIX A}

\section{Guiding Principles for Development}

Conception Bay South Municipal Plan 2011-2021

CBCL Limited, April 2012

The following principles shall be used by Council to guide development of the Town of Conception Bay South over the planning period.

1. Evoke a sense of place - New growth must contribute to a strengthened sense of place through quality development and design that reflects and is compatible with the Town's natural beauty and overall vision.

2. Investing in public places - Visual amenities attract and improve opportunities for economic development. Strategic investment in the public realm to improve vehicular and pedestrian access and safety, the visual appearance and comfort of public spaces, is essential to the future development of the Town as a desirable place to live, work and play.

3. Building and subdivision design to support broader community goals - Each new development within the Town provides an opportunity to enhance its surroundings and contribute to achievement of broader community goals.

4. Foster public health and safety - Public health and safety considerations in the design and management of public places, and in the evaluation of development proposals will ensure the long term health of the community.

5. Embrace practices of environmental stewardship - Preservation and restoration of the natural environment, waterways and wetlands, access to the scenic coastline of Conception Bay, and protection of scenic views will contribute to a sustainable and healthy community.

6. Recognize, anticipate and plan for the impacts of a changing climate - The community is vulnerable to rising sea levels and more frequent and intense storm events. New growth will be planned for safe locations, away from vulnerable areas.

7. Build on existing strengths - Identified strengths of the community - a scenic coastline, linear trail networks, an established agricultural and business community, and arterial road network connections to the Urban Region - will provide the basis for continued community economic development.

8. Provide a balanced network for movement - New growth will contribute to development of an efficient, interconnected network of roads, sidewalks and trails to improve vehicle and pedestrian movement throughout the town. 